\title{
A Method to Simulate Treatment of Thyroid Problems in the Human Body
}

\author{
Rishma Chawla \\ Dept. of CSE \\ RIET \\ Phagwara, Punjab
}

\author{
Yash Pal \\ Dept. of CSE \\ RIET \\ Phagwara, India
}

\begin{abstract}
This is an effort to simulate the concept of treatment of different types of Thyroidism after determining the TSH, T3 and T4 levels in the human body. The target is to determine the effective dose of Thyroxine to be provided to the patient so that normal level of the same can be maintained in the human body. It interacts with every organ system and plays a crucial role in metabolism [1], but there is no software technique to bypass the doctors for the treatment of Thyroid malfunctioning. The Analog devices like operational amplifiers have features identical to the arithmetic operations. Primarily, the voltages in the high-gain dc amplifiers can be reduced to an average to these three variables and the operational amplifiers can do the arithmetic operations on the voltages, the accuracy of measuring voltage may be circumscribed to limited point. A Digital circuit has been implemented to determine the dosage required by the patients using the best market products. The simulation has been done using CircuitMaker ( Student version).
\end{abstract}

\section{Keywords}

TSH (Thyroid Stimulating Hormones), T4( Thyroxine), Neomercazole, Eltroxin and OPAMPs

\section{INTRODUCTION}

Thyroid hormone levels are maintained by a feedback system, which involves the hypothalamus, pituitary gland, thyroid gland, and receptors available in cells as shown in Figure.1[2].

The thyroid, a gland in the Human neck, generates two thyroid hormones, thyroxine (T4) and Tri-iodothyronine (T3). Thyroxine (T4) is not active and is converted by the tissues and organs that need it into tri-iodothyronine (T3) [3]. The role of thyroid hormones are needed for the regulation of metabolism of all the cells in one or another way in the body. When there is not sufficient thyroid hormone (hypothyroidism) the body's metabolism reduces and this is determined by variations in the various tissues [4]. Thyroxine is the major product of the thyroid gland and much of it is later deiodinated in extrathyroidal tissue to form T3. The liver, thyroid, and kidneys have the highest concentration of the type I deiodinase. Other form of this enzyme, type II deiodinase, is found in the brain, pituitary, and skin[5].

The free fraction of $\mathrm{T} 4$ and $\mathrm{T} 3$ in the blood remains more useful parameter of thyroid hormone levels measurement than the total amount of these hormones. This is what is meant by free T4 (FT4) and free tri-iodothyronine (FT3).

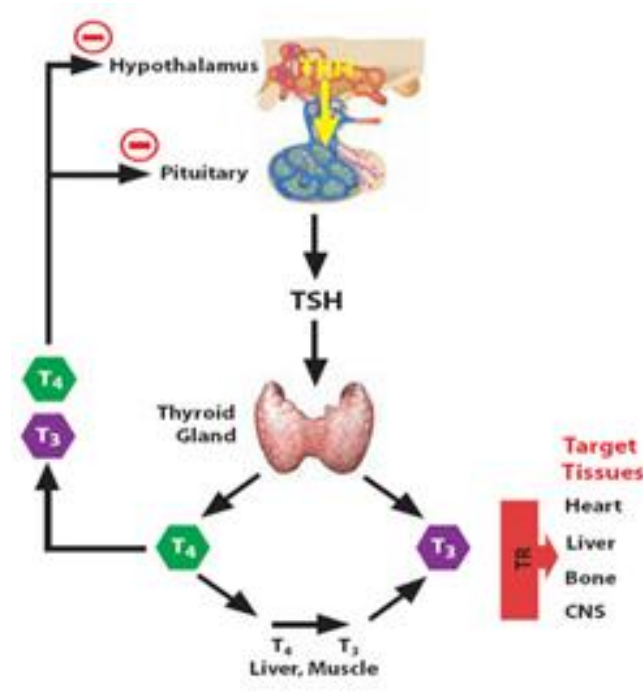

Figure.1:Thyroid hormones

Thus Thyroxine level confirms whether a Human Body is suffering Thyroid disorder or not. The normal ranges for these variables can be given as in Table I and different values of these variables make different types of thyroid disorders as given in Table II[6].

Each component of the hypothalamic-pituitary-thyroid axis can be computed. The concentration of serum TSH can be efficiently measured using an immunoradiometric assay and is often the initial point for an evaluation of thyroid function.

TABLE I NORMAL RANGES
\begin{tabular}{|c|c|}
\hline VARIABLES & NORMAL RANGES \\
\hline TSH & $0.3-3.0(\mathrm{MIU} / \mathrm{L})$ \\
\hline TOTAL T4 & $4.5-12.5(\mathrm{NG} / \mathrm{DL})$ \\
\hline FREE T4 & $0.7-2.0$ \\
\hline TOTAL T3 & $0.60-1.81(\mathrm{NG} / \mathrm{ML})$ \\
\hline FREE T3 & $2.3-4.2$ \\
\hline
\end{tabular}


TABLE II THYROID DYSFUNCTION

\begin{tabular}{|c|c|c|c|}
\hline TSH & T3 & T4 & EXPECTED DYSFUNCTION \\
\hline HIGH & HIGH & HIGH & $\begin{array}{c}\text { MAY BE PITUITARY TUMOR OR } \\
\text { HYPERTHYROIDISM }\end{array}$ \\
\hline LOW & LOW & LOW & $\begin{array}{c}\text { SECONDARY HYPOTHYROIDISM OR } \\
\text { MAY BE PITUITARY FAILURE }\end{array}$ \\
\hline HIGH & NORMAL & NORMAL & $\begin{array}{c}\text { MILD SUBCLINICAL } \\
\text { HYPOTHYROIDISM }\end{array}$ \\
\hline $\begin{array}{l}\text { VERY } \\
\text { LOW }\end{array}$ & HIGH & HIGH & $\begin{array}{c}\text { PRIMARY, FULL-BLOWN } \\
\text { HYPOTHYROIDISM }\end{array}$ \\
\hline LOW & NORMAL & NORMAL & $\begin{array}{c}\text { MILD HYPERTACEMENT } \\
\text { LOW }\end{array}$ \\
\hline HIGH & NORMAL & LOW & $\begin{array}{c}\text { MAY BE SECONDARY } \\
\text { HYPOTHYROIDISM }\end{array}$ \\
\hline
\end{tabular}

Over the last decade, this test has got sophistication.Now AACE advises doctors to observe treatment for patients who test outside the boundaries of a shorter gap based on a target TSH level of 0.3 to 3.0. AACE believes the new range will result in proper diagnosis for millions of Americans who suffer from a mild thyroid disorder, but have not undergone treatment till now. Thyroid hormones (T4 and T3) are produced by the follicular cells of the thyroidgland and are regulated by TSH made by the thyrotropes of the anterior pituitary gland [7].

Thyroxine is produced by attaching iodine atoms to the ring structures of tyrosine molecules. Thyroxine (T4) contains four iodine atoms. Triiodothyronine (T3) is identical to T4, but it has one less iodine atom per molecule [8]

If there is a deficiency of dietary iodine, the thyroid will not be able to make thyroid hormone [9]. The deficiency of thyroid hormone will result in diminished negative feedback on the pituitary, leading to increased production of thyroid-stimulating hormone, which causes the thyroid to increase in the size. This problem is called goitre.

\section{COMMON TREATMENT}

Thyroid dysfunction can be mainly classified as

i) Hypothyroidism

ii) Hyperthyroidism

Following steps [10] may be used, although the order of them and the number that may need further pursuit may vary from one patient to the next, based upon the individual patient's circumstances. i) Confirm the diagnosis and laboratory results.

ii) Ask about compliance

iii) Check the patient's medication bottles and tablets.

iv) Review the thyroxine ingestion history.

v) Investigate for malabsorption.

vi) Consider increased turnover or excretion.

vii) Perform a thyroxine absorption test.

viii) Treat the patient.

After proper diagnosis of hypothyroidism, the next issue is with what substance to treat.. The traditional approach is to use Synthroid/ Levoxyl/Levothroid (levothyroxine) which is only T4. Natural medicine doctors tend to use Armour thyroid which is a mixture of mono and di-iodothryonine and $\mathrm{T} 3$ and $\mathrm{T} 4$, the entire range of thyroid hormones[11]. If Thyroid Antibodies are tested positive, it indicates that the Thyroid is in the process of Autoimmune failure [12]

\section{THEORETICAL ASPECTS}

To simulate the proposed circuit, we can use an analog method by the use of operational amplifiers. An analog method can be applied to find solutions of a number of differential equations, linear equations etc [13]. Then a digital circuit is used to determine the dosage of treatment requied by the patient making it a hybrid approach.

Refer [6] electronic circuit diagram for the proposed device. There were six Ideal OPAMPs[14] (U1A, U1B, U2, U3, U4, U5) which had been used for implementation of TSH level interpretation. The circuit was implemented using four multimeters[15] so that output of each OPAMP could be watched. The Vs1 represented the TSH level of Human Body. If the output of $\mathrm{U} 3$ and $\mathrm{U} 4$ were both high $(9.984 \mathrm{nV})$ then the TSH level (> $3.0 \mathrm{uIU} / \mathrm{mL}$ ) was high [16]. If the outputs of both OPAmps were low $(4.898 \mathrm{~V})$ then the TSH level $(<0.3 \mathrm{uIU} / \mathrm{mL})$ was low. If the output of $\mathrm{U} 3$ was high and $\mathrm{U} 4$ was low then the human body was having TSH level in the normal range.

The instance of the circuit showed Vs1 $=0.72 \mathrm{~V}$ that was the TSH level was between normal range. We were representing the single unit of TSH $(1 \mathrm{uIU} / \mathrm{mL})$ by $1 \mathrm{~V}$ of the voltage supplies). In the given circuit, the ideal OPAMP U5 output was the negative of input Voltage. Thus, the output represented $+\mathrm{TSH}$.

The ideal OPAMP U1A was a comparator[17]. The comparator compared the linear voltage applied on the negative terminal with the voltage applied on the positive voltage. If the voltage on positive terminal was greater than on the negative terminal, the output was high $(9.984 \mathrm{nV})$, otherwise low (4.898V). It compared the reference lower limit of TSH that was 0.3 with 


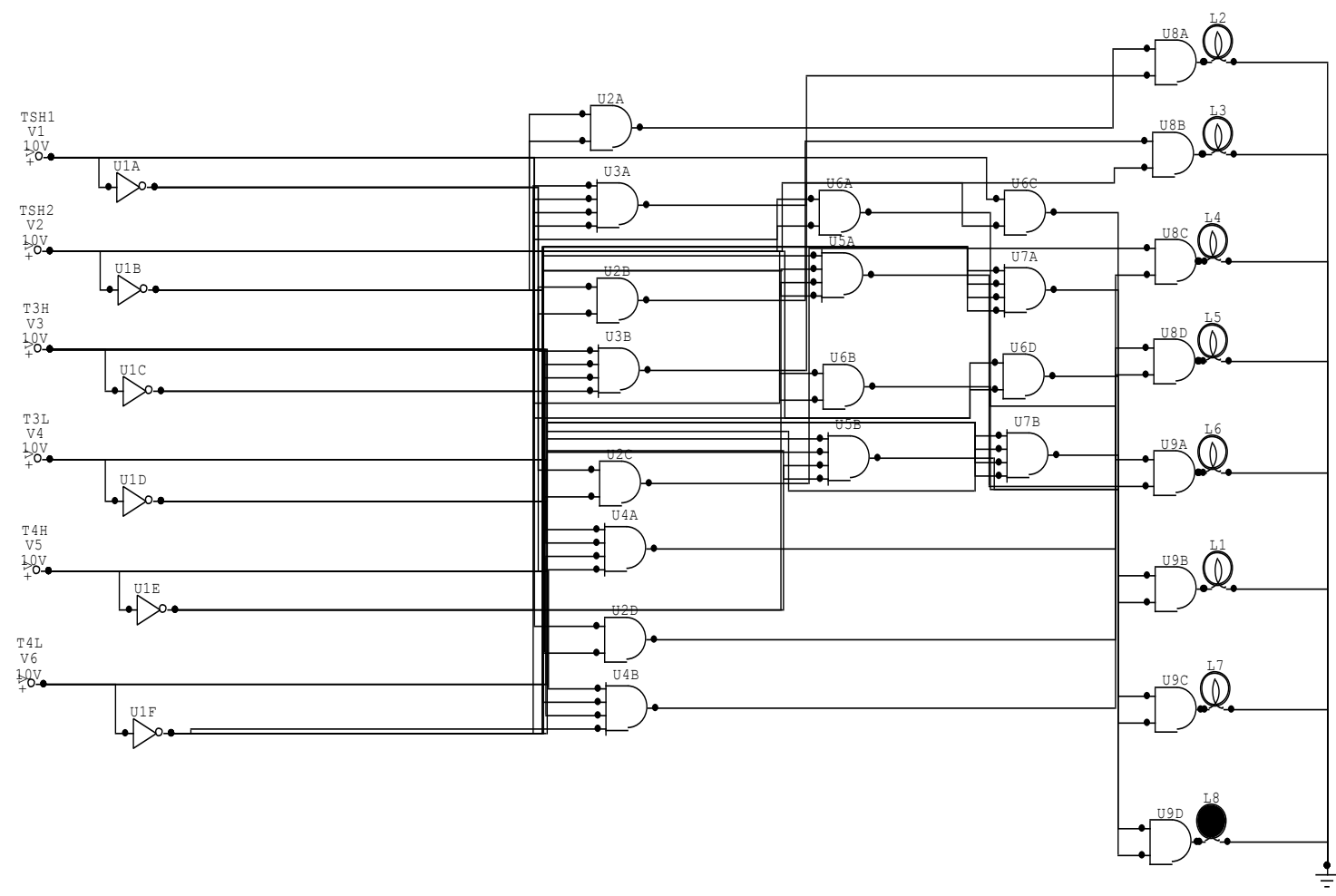

Figure. 2: Simulation for determination of Thyroid Dysfunction using Circuit Maker

\section{TABLE III: BEST MARKET MEDICINES FOR DIFFERENT TYPES OF THYROIDISM}

\begin{tabular}{|c|c|}
\hline Thyroid Dysfunction & $\begin{array}{c}\text { Treatments for the } \\
\text { different Types of the } \\
\text { Thyroid Disorders given in } \\
\text { TABLE IV }\end{array}$ \\
\hline $\begin{array}{c}\text { MAY BE PITUITARY TUMOR OR } \\
\text { HYPERTHYROIDISM }\end{array}$ & 20 MG NEOMERCAZOLE \\
\hline $\begin{array}{c}\text { SECONDARY HYPOTHYROIDISM } \\
\text { OR MAY BE PITUITARY FAILURE }\end{array}$ & 25 MCG THYRO-3 \\
\hline $\begin{array}{c}\text { MILD SUBCLINICAL } \\
\text { HYPOTHYROIDISM }\end{array}$ & 25MCG ELTROXIN \\
HYPOTHYROIDISM & 100 MCG ELTROXIN \\
\hline $\begin{array}{c}\text { PRIMARY, FULL-BLOWN } \\
\text { THERAPY OR HYPERTHYROIDISM }\end{array}$ & 10 MG NEOMERCAZOLE \\
\hline MILD HYPERTHYROIDISM & 5 MG NEOMERCAZOLE \\
\hline MAY BE SECONDARY \\
HYPOTHYROIDISM
\end{tabular}

recorded TSH level. It gave the high output $(9.984 \mathrm{nV})$ because $0.72>0.3$.

Similarly, the ideal OPAMP U1B was a comparator for comparing the higher limit that is $3.0 \mathrm{uIU} / \mathrm{mL}$ with the recorded TSH level. In the same way we could construct the circuits for Total T3 and Total T4 and find the possibility of type of Thyroid dysfunction. The truth table for circuit for interpretation of Thyroid dysfunction is given in Table IV.
As the digital circuit in Figure. 2 shows, the lamp which ignites gives the indication for the treatment of the Thyroid disorder as per TABLE III. If the first lamp at the top ignites, we can infer that the disorder is Hyrperthyroid or pituitary tumor and treatment is $20 \mathrm{mg}$ Neomercazole. Similarly, other inferences can be deducted.

\section{TABLE IV}

TRUTH TABLE FOR DISEASES IN TABLE II
\begin{tabular}{|c|c|c|c|c|c|}
\hline TSH1 & TSH2 & T3H & T3L & T4H & T4L \\
\hline 0 & 0 & 0 & 0 & 0 & 0 \\
\hline 0 & 0 & 1 & 0 & 1 & 0 \\
\hline 0 & 0 & 1 & 1 & 1 & 1 \\
\hline 1 & 0 & 1 & 0 & 1 & 0 \\
\hline 1 & 1 & 0 & 0 & 0 & 0 \\
\hline 1 & 1 & 1 & 0 & 0 & 0 \\
\hline 1 & 1 & 1 & 0 & 1 & 0 \\
\hline 1 & 1 & 1 & 1 & 1 & 1 \\
\hline
\end{tabular}

\section{CONCLUSION}

In an analog computer simulation there are so much assumption in deriving the relationships for operational amplifiers. Accuracy of voltage is upto a certain limit. So we have an analog computer applied for a single problem. We have designed a hybrid representation of a thyroid system which is more natural in the meaning that it simplifies the implementation of simulation and comprehension of the results. 


\section{FUTURE WORK}

As TSH, T3 and T4 levels are determined and type of dysfunction is confirmed, the accurate dosage can be calculated by applying interpolation methods in MATLAB and the corresponding best fitted equations can be implemented in the Circuit-maker. And the medicines available in the market can be produced in different varieties.

\section{REFERENCES}

[1] Becker KL, Smallridge RC, Wartofsky L. Part III: The thyroid gland. Chapter 33: Thyroid function tests. In: Principles and Practice of Endocrinology and Metabolism. 3rd ed. Philadelphia, PA: Lippincott Williams \& Wilkins; 2002.

[2] Braverman LE, Utiger RD, eds. The Thyroid: Fundamental and Clinical Text. 9th ed. Philadelphia, PA: Lippincott Williams \& Wilkins; 2005.

[3] Jose Ramon Alvero, Cruz, Mauro Ronconi, Margarita, Carrillo De Albornoz, Gil, Jeronimo C., Garcia Romero, Daniel Rosado Velazquez, A. Mario De Diego Acosta, Thyroid hormones response in simulated laboratory sprint duathlon, Journal Of Human Sport \& Exercise, ISSN 1988-5202, 2011

[4] Eisenberg M1, Samuels M, DiStefano JJ 3rd., Extensions, validation, and clinical applications of a feedback control system simulator of the hypothalamo-pituitary-thyroid axis, doi: 10.1089/ thy.2007. 0388, 2008.

[5] Maia AL, Kim BW, Huang SA, et al. Type 2 iodothyronine deiodinase is the major source of plasma T3 in euthyroid humans. J Clin Invest. 2005:115;25242533.

[5] AACE press release of January 2003.

[6] Yash Pal, Vikas Verma, Rishma Chawla, “Determination of Thyroid Disorders in the Human Body using TSH, T3 and T4 levels", International Journal of Computer Applications(0975-8887), Volume 94-No.8, May, 2014.

[7] Nicoloff JT, Spencer CA. The use and misuse of the sensitive thyrotropin assays. J Clin En-docrinol Metab. 1990;71:553-558. [7] I.S. Isa, Z. Saad, S. Omar, M.K. Osman, K.A. Ahmad, H.A. Mat Sakim, "Suitable MLP Network Activation Functions for Breast Cancer and Thyroid Disease Detection," cimsim, pp.39-44, 2010
Second International Conference on Computational Intelligence, Modelling and Simulation, 2010.

[8] Walter F., PhD. Boron , Chapter 48, "Synthesis of Thyroid Hormones Medical Physiology: A Cellular And Molecular Approach,” Elsevier/Saunders. p. 1300. ISBN 1-4160-2328-3 2003.

[9] Professor G. Wainer, "Modelling and Simulation of the Human Liver," Biomedical Applications, Department of Systems and Computer Engineering, Faculty of Engineering, Carleton University.

[10] Georg Hennemann, Roelof Docter, Edith C. H Friesema, Marion de Jong, Eric P. Krenning and Theo J. Visser, "Plasma Membrane Transport of Thyroid Hormones and Its Role in Thyroid Hormone Metabolism and Bioavailability, Endocrine Reviews". August 2001, 22(4):451-476.

[11] John C. Morris, "How do You Approach the Problem of TSH Elevation in a Patient on High-dose Thyroid Hormone Replacement?" Disclosures, Int J Qual Health Care. 2009;70(5):671-673.

[12] John B. Tourtelot, Assistant Clinical Professor of Medicine, University of South Florida, Tampa, FL, RPh, MD, "Precise Dosing of Levothyroxine" Disclosures, June 1, 2007, Supported by Abbott Laboratories.

[13] Murray, Francis J., Mathematical Machines, vol.2 Analog Devices, New York: Columbia Press, 1961.

[14] Walt Kester, Editor, High Speed Design Techniques, Analog Devices, 1996, ISBN0-916550-17-6.

[15] Robert Paz, Analog Computer Programming

[16] Pierre-Frederic Villard, Piers Boshier, Fernando Bello and Derek Gould, "Virtual Reality Simulation of Liver Biopsy with a Respiratory Component." Imperial College, London, LORIA, Nancy University, Royal Liverpool Hospital, Liverpool.

[17] Yash Pal, "An Analog Method to study Average Memory Access time in a compuer system," Proceedings of the World Congress on Engineering, 2013 Vol II, London, UK, 2013

[18] Alpco Diagnostics, "T4 (Thyroxine) (Free) LIA For the quantitative determination of of free T4 in serum," Version: 5.0 May 18, 2011 - ALPCO, 2012 